\title{
LA LEYENDA ÁUREA DEL SEPARATISMO EN CUESTIÓN
}

\author{
Alberło J. Gill lbáñez \\ Doctor en Derecho Europeo (IUE, Florencia) \\ Doctor en Ciencias de la Religiones (IUCCRR, UCM, Madrid)
}

https://doi.org/10.33676/EMUI_nomads.57.02

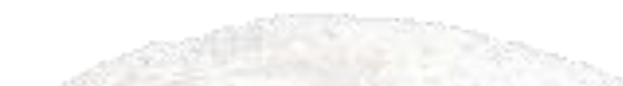

Resumen: El separatismo catalán para legitimar sus pretensiones necesita construir un relato atrayente y luminoso de la Historia de Cataluña (leyenda áurea) que contrapone a la consabida leyenda negra española, corregida y aumentada con nuevas-viejas sombras y núbarrones. Esta contraposición, sin embargo, se fundamenta en un conjunto de "fake-stories" -falsificaciones, ocultaciones o exageraciones-, cuidadosamente escondidas y disfrazadas bajo una narración pretendidamente "objetiva" e intachable. Este artículo trata de desenmascarar esta estrategia manipuladora, desvirtuando uno por uno los mitos del separatismo, al tiempo que se destaca el papel histórico y político real de Cataluña y su relación con el resto de España
\end{abstract}

Palabras clave: fake-stories, separatismo, nacionalismo, secesionismo, Cataluña, España, leyenda negra

\section{The aurea legend of separatism in question}

Abstract: Catalan separatism requires, in order to legitimize its claims, to build an attractive and luminous account of the history of Catalonia (Golden leyend). This narrative has to be oppossed to the well-known Spanish black legend, revised and increased with new-old shadows and clouds. This contrast, however, is based on a set of "fake-stories", carefully hidden and disguised under a purportedly "objective" and unimpeachable narrative. This article seeks to unmask this manipulative strategy, debunking one by one the myths of separatism, while highlighting the real historical and political role of Catalonia and its relationship with the rest of Spain

Keywords: fake-stories, separatism, nationalism, secessionism, Catalonia, Spain, black legend

\section{1. "Fake-stories" al servicio de la ideología separatista}

¿Por qué "una parte de" los catalanes quieren separarse del resto de españoles? Un asunto complejo que admite varias interpretaciones. No hay que menospreciar las consecuencias de la crisis de las ideologías y las religiones o la tendencia tradicional de los (territorios) más ricos a ignorar lo que deben al resto, llegando a considerar un coste inaceptable su obligación de solidaridad con los demás. De hecho, en el año 2012 el semanario alemán Der Spiegel publicó un reportaje titulado "La hora de los egoístas" donde se analizaba el caso español señalando que "la crisis 
impulsa a los separatistas en varios países de la UE y las regiones ricas ya no sienten la solidaridad con las regiones más pobres del país".

En todo caso el separatismo para convencer "ad intra" y "ad extra" de su legitimidad y justificación necesita un relato que lo sostenga. Y este relato se ha creado de forma consciente y detallada sobre una doble vara de medir ya clásica: Cataluña sería una vieja-moderna nación con una historia plagada de luces (leyenda áurea), frente a una España oscura, sombría, inclasificable, primitiva y anti-democrática, un conjunto inconexo de pueblos, pero paradójicamente lo suficientemente poderosa como para someter de forma tiránica al pueblo catalán durante siglos (leyenda negra). De esta manera se resucita el sempiterno relato hispanófobo que resuena lamentablemente todavía en la memoria de algunos europeos (ver G. Ibáñez, Alberto, 2018).

Esta contraposición leyenda áurea-leyenda negra no es nueva. De hecho, todo nacionalismo es consciente de la importancia de manipular la Historia para crear un pasado "mítico" que sirva para legitimar sus pretensiones. Pero en el caso catalán se ha llegado probablemente al paroxismo pues no es sólo que se exageren u oculten hechos, es que directamente se desvirtúa el pasado y el presente, creando diversas leyendas falsas: ni existe una base histórica que haga de Cataluña un territorio esencialmente más singular que otras regiones de Europa (o de España), ni ha sido tradicionalmente postergada o maltratada por el "gobierno de Madrid", ni España es hoy un país atado por su herencia franquista que no reconoce y protege los derechos de todos sus ciudadanos.

Todo lo contrario. Cataluña se ha visto favorecida tradicionalmente por el gobierno español que aprobaba leyes proteccionistas para sus productos (que perjudicaban a la productividad del resto) o que la beneficiaban de otro modo en relación con los demás (incluso duranfe el régimen franquista). España no ha robado (Castilla es quien ha soportado históricamente el mayor peso fiscal del funcionamiento del Imperio y sus reyes hasta quedar exhausta) ni roba hoy a Cataluña como han demostrado los catalanes Josep Borrell y Joan Llorach (Las cuentas y los cuentos de la independencia, 2015) quienes analizan la falsedad del discurso económico nacionalista y el tramposo cálculo de las balanzas fiscales.

Otro tanto podría decirse det discurso "victimista" en cuanto a falta de inversión del Estado en Cataluña: hoy esta región se beneficia del 24,7\% del total de capital público del Estado de ferrocarriles; el $19 \%$ del stock en aeropuertos; el $16 \%$ del de puertos; y el $13,2 \%$ del de carreteras. ${ }^{1}$ Por cierto, tanto en carreteras como en ferrocarril notablemente superior al

\footnotetext{
1 Cfr. Informe del Instituto de Estudios Económicos (junio, 2019), "La inversión del Estado en infraestructuras de transporte en Cataluña y otras Comunidades Autónomas"
} 
de Madrid, y en el resto superior al de la mayoría de las Comunidades Autónomas (Madrid no tiene puerto, obviamente).

No obstante, en este artículo nos proponemos desmontar en particular la narrativa histórica fantasiosa que ha creado el separatismo: un conjunto de falsedades, ocultaciones interesadas y exageraciones. Para justificar su extraordinaria singularidad (y superioridad) manifiesta, previa y separada de España todo vale, hasta declarar a Colón y Santa Teresa eran catalanes de pura cepa, como defiende el "Cercle Català d'Història" (www.cch.cat). Pero sus principales mitos se desmontan solos para quien se tome la molestia de estudiarlos:

\section{Cataluña: ¿una nación milenaria, independiente y anterior a España?}

Los separatistas sostienen que España no había existido como nación, pero Cataluña sí y desde antiguo. Aquí el truco es jugar con el significado de "nación", diferenciándola de imperio o reino. Incluso así, España sería una de las primeras naciones modernas calificada como tal en su Constitución de 1812, cuya aprobación fue apoyada singularmente por los diputados catalanes. Por eso el separatismo suele pasar por alto la relevancia de este texto. En todo caso, mirando hacia atrás y para no caer en la trampa nominalista, cabe preguntarse cuándo y durante cuánto tiempo España y Cataluña fueron consideradas como "comunidades políticas claramente diferenciadas e identificadas como tales", tanto internamente (por sus habitantes) como externamente (por el resto).

España es una comunidad política reconocida internacionalmente como tal desde hace al menos 500 años, mientras Cataluña nunca ha sido una comunidad política independiente. No llegó a la categoría de reino; fue un conjunto de condados o un principado, y hoy una Comunidad Autónoma. Entre los pueblos pre-romanos no había catalanes ni nadie hablaba de Cataluña. El actual territorio catalán estaba poblado mayoritariamente por íberos, en una fusión de pueblos no muy diferente del resto de la península, uno de los primeros lugares de Europa donde habian compartico terreno desde antiguo cromañones y neardentales (Alfonso Moure Romanillo y Juan Santos Yanguas, 2004; Varios autores, 2004).

Durante el Imperio romano formó parte de "Hispania", con Tarraco como capital de la Hispania citerior en el año 25 A.C. Concretamente desde el año 29 A.C, las provincias de Hispania eran cinco: Tarraconensis, Carthaginensis, Gallaecia, Lusitania y Baetica; no existía Cataluña. Durante la España visigoda, que llegó con Leovigildo a dominar casi toda la península y con Recaredo a tener una religión común (el catolicismo), un periodo que duró 130 años, Cataluña tampoco existía ni era mencionada. Mientras España no se convirtió en Visigotia (como Francia 
con los francos) sino que continuó con el nombre que existía incluso antes de los romanos, del que se dice se lo dieron los fenicios.

Durante el dominio árabe, la actual Cataluña siguió sin existir como entidad autónoma y homogénea. Se dividió en dos: el norte pasará a depender de los reyes carolingios y franceses a partir de 795, bajo el nombre de ¡Marca Hispánica! ¿Por qué ese nombre? Pues porque el patronímico "español", paradójicamente, no es de origen español ni castellano, sino de origen lemosino y surge en la Edad Media al emplearse por parte de los habitantes del sur de Francia (es decir de un tercero) en su relación con los que cruzaban los Pirineos huyendo de la invasión musulmana, procedentes de la Península ibérica, es decir en su mayoría de tierras catalanas... De ahí el nombre de "Marca hispánica", por eso se oculta.

Todavía en el 809, bajo el mitificado conde Wilfredo el Velloso, Cataluña no era más que un conjunto de condados, el más importante de ellos el de Barcelona. Para la propaganda separatista, Cataluña surgiría como entidad política al separase sus "condes" (fundamentalmente Borrell II, conde Urgell) del Imperio carolingio en 987. En realidad, el nombre de Cataluña no aparecería hasta 1114 con Ramón Berenguer III, pero poco después, en 1150, Ramón Berenguer IV (1113-1162), conde de Barcelona, Gerona, Osona, Cerdaña y Ribagorza lesos eran los condados catalanes), decidió cambiar su título de conde por el de "princep de Aragón", aceptando incorporar sus condados al reino de Aragón que regía Petronila (hija del rey Ramiro el Monje), con quien se casó, a cambio de que su hijo Alfonso II (1 157-1 196) fuera rey de Aragón. Es decir, que la Cataluña independiente (si bien como un conjunto de condados, dominados por el de Barcelona) duró 36 años.

El Reino de Aragón, andando el tiempo, abarcaría Valencia, las Mallorcas, Barcelona, Sicilia, Cerdeña, Nápoles, el Rosellón y la Cerdaña. Su capital fue Zaragoza e incluso Valencia (allí se trasladó Alfonso V, 14161458), no Barcelona y participó junto al resto de reinos de España en la reconquista del dominio árabe de forma entusiasta. Incluso cuando se refiere a Martín el Humano (1356-1410) como el último rey catalán, realmente era solo descendiente tanto de Berenguer como de Petronila, y formalmente fue rey de Aragón y Valencia y Conde de Barcelona. En todo caso, tras morir sin descendencia, y conformo a lo acordado en el compromiso de Caspe, reinarán después los Frastamara, que ya no tendrán restos de sangre catalana.

Esta "dura realidad" la propaganda separatista la ha intentado solventar cambiado la denominación "Corona de Aragón" por "Corona catalanoaragonesa", o "Confederación catalano-aragonesa", pero se trata de una mera invención introducida artificialmente por el catalanismo en 1869 cuando un estudio sesgado de Antonio de Bufarull obtiene el premio del Ateneo catalán. Como ha señalado la Asociación de Historiadores de Cataluña "Antoni de Campany" (cfr. Nota de prensa de 23 de enero 
de 2018), esa expresión no solo ignora la historia real, sino que desprecia a dos grandes reinos de la corona (Valencia y Mallorca) además de otros que lo fueron según qué periodo (Nápoles, Cerdeña y Sicilia), por parte del único territorio que nunca fue reino y que aun así pretende ocupar el lugar preeminente

Cuando se dice que Jaime I (1208-1276) era un rey catalán, fue porque decidió formar Cataluña haciendo vasallos del Condado de Barcelona a los Condados de Empúries, Urgell y Pallars Sobirá. Desde entonces todos los condados catalanes formarán parte del reino de Aragón con un estatuto similar al de otras partes del mismo, con sus fueros e incluso con el título de principado, pero nunca alcanzará el estatuto de "reino", a diferencia de Navarra, Valencia o el mismo Aragón, todos ellos hoy paradójicamente con mucho menos "legitimidad" soberanista. De hecho, en época de Jaime I (rey de Aragón y conde de Barcelona y Urgell) los cinco reinos de España eran: Aragón, Castilla, León, Portugal y Navarra. Todavía no aparecía Cataluña (ni el País Vasco). A este respecto una de las cuestiones más tergiversadas es la cuestión del origen de la bandera catalana (senyera). Más allá de la mercadotecnia independentista, lo cierto es que las barras de Wilfredo el Velloso -supuesto origen de las banderas catalana, valenciana y mallorquinaeran las armas del reino de Aragón, siendo utilizadas las cuatro barras por primera vez en el sello real Alfonso Il, rey de Aragón.

Otro episodio relevante que se pasa por alto es que antes de que los Reyes Católicos unieran las Coronas de Castilla y Aragón, en 1462, los diputados del General (que erróneamente los separatistas identifican con la actual Generalidad de Cataluña), se sublevaron contra su rey Juan II (de Aragón) y proclamaron a Enrique IV de Castilla como su soberano, jurando "que sia feta perpetual unió e incorporació de aquest Principat ab lo Regne de Castella" (Cfr. J. Marías, 2010, p. 138). Nada más y nada menos que "perpetua unión e incorporación". Un juramente que pronto se quebraría. No sería el último, y eso en la tierra que presume de ser fieles a la palabra dada.

En 1469 contraen matrimonio Isabel I de Castilla y Fernando II de Aragón, y a partir de 1475 (Tratado de la Concordia de Segovia) unen sus reinos. Las dudas sobre si a su muerte los dos reinos volverían a separarse se resolvieron definitivamente con el ascenso al trono de Carlos I de España (y $\vee$ de Alemania), nieto común de ambos. A parfir de entonces nunca más se volverá a plantear una España dividida en dos (el primer rey que gobernó sobre todos los territorios británicos fue Jacobo I en 1603). Conviene dejar igualmente claro que España no se creó por interés de Castilla (que miraba a África y el Atlántico), sino más bien por interés de Aragón (que miraba al Mediterráneo). En los tiempos previos a los Reyes Católicos, Castilla dudaba entre Portugal y Aragón. Fue el reino de Aragón (donde quedaba incluida Cataluña) el más decidido a recuperar la idea de una España fuerte precisamente porque eran los 
que más sufrían las acometidas del vecino francés. En este sentido destacó, entre otros, el cardenal y canciller Joan Margarit (1422-1484), principal asesor de Juan II, padre de Fernando el católico.

¿ Dónde queda pues la singularidad histórica y política específica de Cataluña? Pues cabe hablar de un corto periodo de tiempo donde una serie de condados catalanes estuvieron bajo el mismo conde y este periodo no llegó a cuarenta años. Según el historiador Salvador de Madariaga (1979, pp. 168-169) la época de mayor esplendor de Cataluña nació en la Edad media y murió con ella, compartiendo el destino de otras entidades semejantes (incluso con más méritos para considerarse independientes) como Escocia, Borgoña, Saboya o Venecia. La comparación con Venecia a este respecto resulta paradójica, ya que ésta fue realmente una ciudad-Estado independiente durante siglos mientras hoy forma parte de un país como Italia sin reclamar privilegios, ni referéndums y hablando el italiano (antiguo toscano) sin conflictos ni problemas, a pesar de ser una lengua menos relevante en el mundo que el español.

\section{El Mediterráneo: ¿un imperio "sólo" catalán?}

La leyenda aurea catalana trata de mistificar el imperio mediterráneo -que sería supuestamente "sólo" catalán y por tanto el bueno-frente al imperio americano -que sería castellano, y por tanto el malo-. Pero esta simplificación tampoco es cierta. En 1492 Castilla contaba con cuatro millones de habitantes y Aragón (incluida Cataluña) con poco más de medio millón. ${ }^{2}$ La dinastía trastamara dominaba España sin hacer distingos, y de hecho fue bajo mandato de Isabel y Fernando cuando las posesiones mediterráneas se mantuvieron y extendieron gracias al Gran Capitán (Gonzalo Fernández de Córdoba) y a los soldados procedentes de toda España. Tampoco se quiere recordar que la catedral de Barcelona pudo construirse gracias a que la reina Isabel de Castilla empeñó sus joyas a tal fin, como nos recuerda el hispanista Hugh Thomas (2003, p. 92). O que el Rosellón y al Cerdaña se recuperaron también en la misma época (1493) con los mismos reyes y una España unida frente a Francia, aunque luego se perderían por culpa de la revuelta catalana de 1640.

Es más, la leyenda negra antiespañola surge en Italia no en América (Cfr, Sverker Arnoldsson, Los orígenes de la leyenda Negra española, 2018) por la actividad... de los catalanes que por allí aparecieron, aunque acabara por afectarnos a todos pues a los catalanes ya en pleno siglo

\footnotetext{
2 Los datos demográficos son importantes para ver la entidad de las reclamaciones políticas de unos y otros. J. Elliott (2018, p. 40) cita que en 1530, la Corona de Castilla contaba con cuatro millones de habitantes (el mismo número que Inglaterra y Gales juntas) mientras que en Aragón vivían 779.000 habitantes, de los cuales 250.000 aproximadamente eran catalanes. Enlal misma época había entre 500.000 y 700.000 escoceses
} 
XV se les tenía por españoles. Decía Farinelli: "Da un lembo de la Spagna, dalla Catalogna, a noi più vicina, giudicavisi l'intero paese". El propio Dante Aliguieri, en el siglo XV recogía el desprecio que los italianos sentían por los catalanes: "Si mi hermano pudiera prever esto/ evitaría la pobreza avara de los catalanes, para no recibir ningún daño»l (Divina Comedia, "Paraíso", canto VIII). Y para Benedetto Croce (España en la vida italiana) "Por todas partes dominan los catalanes y Dios sabe hasta qué punto son insoportables con su dominio"'. Por tanto, este desprecio (injusto y exagerado) dirigido a los catalanes era recibido como destinado a todos los españoles (incluidos los dos papas de la familia Borgia), pues así éramos considerados todos.

De esta mala fama el resto de españoles no ha pedido nunca cuentas a los catalanes. Curiosamente, no ocurre lo mismo cuando se trata de contrarrestar la mala fama de los españoles en América, acusación de la que los separatistas pretenden librarse como si no fuera con ellos aunque muchos catalanes participaran en la Conquista.

\section{4. ¿Por qué se olvida la rebelión de 1640 ?}

¿Por qué el separatismo centra todas sus quejas en la guerra de sucesión (1702-1713) y olvida la rebelión de 1640-1652? Se trata de un suceso mucho más importante para la historia de Cataluña (de lo que pudo haber sido y no fue) y que "curiosamente" la historiografía separatista suele ocultar. ¿2Por qué ignorar los únicos "12 años" de la Historia donde Cataluña ha sido realmente independiente de España o de Aragón? Pues tal vez porque todo ese esfuerzo sirvió para pasar... a depender de Francia, con un rey mucho más centralista.

La rebelión se produjo por la resistencia catalana a la Unión de Armas, que a iniciativa del Conde-Duque de Olivares (valido-primer ministro del rey español Felipe IV), proponía un reparto más justo de la aportación de los diversos territorios al ejército de la Corona. Cataluña se negó (egoístamente) en varias ocasiones, si bien no tuvo luego reparos en pagar a Francia mucho más para defenderla de España. Curiosa y paradójicamente los fondos que los catalanes entregaron a los franceses para financiar un ejército de 3.000 hombres, fueron utilizados para conquistar el Rosellón, Vallespir, Conflent, Capcir, La Cerdaña, Artois, Luxemburgo y diversas plazas en Flandes, territorios que ya nunca devolvería a ser españoles ni catalanes (Tratado de los Pirineos de 1660). Es más, en la parte anexionada por Francia el rey Luis XIV (más centralista que el español) acabaría prohibiendo el uso del catalán.

Poco después de la rebelión, en 1645, el obispo de Vic (hoy núcleo duro del separatismo) escribiría al rey español pidiendo que interviniera de inmediato para que impusiera "la justicia como en Castilla" y acabara con los fueros y abusos arbitrarios de los grupos poderosos. Son igualmente famosas las quejas del campesinado (los famosos "segadors" 
que dan nombre al Himno catalán) frente a los abusos de los dirigentes catalanes. Como consecuencia, cuando finalmente Felipe IV decide entrar en Barcelona en 1652 y enfrentarse a la oligarquía catalana será recibido por masas empobrecidas y sangradas por sus señores al grito de "Viva la santa fe católica y el rey de España y muera el mal gobierno". La Corona francesa se reveló mucho más terrible y egoísta que la ingenua monarquía española, que no tomó sorprendentemente ninguna represalia a pesar de la traición. Es más, uno de los "héroes" de esta rebelión (y hoy del nacionalismo) Pau Claris murió arrepentido de su acción, tras haber proclamado al centralista LUis XIII conde de Barcelona. Otro héroe falsificado.

En realidad, para este viaje no hacían falta alforjas. De hecho, si se hubiera accedido a la unión de armas probablemente España no habría perdido territorios y habría, al menos, retrasado su decadencia en relación con Francia. ¿̇Y qué habría pasado si entonces Felipe IV hubiera hecho algo parecido a lo que hizo Felipe II ante el levantamiento de Zaragoza de 1591-1592, cuando obligó a las Cortes de Aragón a aceptar limitaciones a la autonomía de que disfrutaban bajo la antigua Constitución aragonesa? Nunca lo sabremos aunque es fácil de imaginar.

\section{La fecha mítica de 1714 ¿una terrible invasión española que destruyó la soberanía catalana?}

Una fecha clave para el misticismo separatista es 1714. Pero en realidad, lo que se ha vendido falazmente como una guerra entre Cataluña, apoyada por el rey austríaco, y el resto de España, apoyada por el rey francés, dista de ser cierto. Si los europeos conocieran su propia historia sería bastante fácil derrumbar esta fantasía, pues nos encontramos no ante una guerra entre españoles y catalanes sino ante la que se considera la primera guerra civil europea, tanto política (se jugaba el predominio de Francia o el resto) como comercial (todos buscaban hacerse con los derechos de comercio con América).

La guerra de sucesión (que no de "secesión") española (1702-1713) contó con partidarios de ambos reyes (el borbón y el austríaco) a lo largo de todo el territorio español. De hecho, lo "natural" era que a un austriaco (Carlos II) le hubiera sucedido otro de similar dinastía, pero todo cambió fruto de un conjunto de pactos y enrevesadas estrategias. En los años previos a la muerte de Carlos II las potencias europeas hicieron todo tipo de acuerdos y componendas cara a un reparto por trozos de España y de sus posesiones. Una de las que casi siempre salía perdiendo en esos repartos era precisamente Cataluña, que era troceada o pasaba 
directamente a ser parte de Francia, un país que no se ha caracterizado históricamente por respetar las singularidades territoriales. ${ }^{3}$

Si Felipe $\vee$ pudo finalmente optar a la corona española y por tanto romper con la tradición austríaca fue debido al testamento que otorgó, no sin muchas dudas y reservas, Carlos II, al morir sin descendencia. El cambio de voluntad de Carlos II a última hora-debido a las múltiples presiones recibidas - le abrió la puerta. Este cambio fue favorecido por el Cardenal Portocarrero y un grupo de asesores - que obedecían instrucciones y dineros del embajador francés Harcourt, quien había prometido al cardenal el solio pontificio- y gracias al oportuno alejamiento, pará reprimir el "motín de los gatos", del conde de Oropesa y el Almirante de Castilla. ${ }^{4}$

En todo caso una vez nombrado Felipe $V$ como sucesor, los catalanes... lo aceptaron. En 1701 Cataluña había recibido a Felipe de Anjou con grandes muestras de adhesión y en 1705 las cortes catalanas le prometieron fidelidad a cambio del mantenimiento de varios privilegios. Fueron los representantes catalanes los que luego cambiaron de opinión y en mitad de la carrera pasaron a apostar por Carlos porque "supuestamente" les ofrecía más, faltando una vez más a su palabra y juramento. Resulta curioso que los mismos que habían corrido a pedir la ayuda y ofrecer su vasallaje a los borbones como reyes franceses en 1640, acabaran rechazando al borbón como rey español.

Estos hechos se olvidan cuando se critica que Felipe $\vee$ fuera reacio a mantener fueros y privilegios. Ello no fue solo (que también) porque en esa época los fueros se consideraban ya como reliquias medievales (de hecho en Francia no quedó ni uno) y porque el rey considerara más eficaz y práctico para el funcionamiento del reino contar con un derecho público común - el derecho privado especial catalán sí se respetó- sino porque se había sentido traicionado por unas cortes catalanas a las que no dudó en calificar de perjuras. Es decir, que si no hubieran cambiado, cual veletas, de opinión (y de rey) habrían salido mejor paradas con un acuerdo que ya habían aceptado y que por tanto no consideraban tan malo.

En este sentido también se ha hablado de un incipiente parlamentarismo catalán que habría sido protegido de haber ganado los ingleses. Pero esto tampoco es cierto. Curiosamente en el mismo año (1707) que tiene lugar la batalla de Almansa, donde pierden las tropas anglo-austriacas,

\footnotetext{
3 Ver para un resumen de estos acuerdos: Ricardo García Cárcel "La guerra de Sucesión, una guerra poliédrica", en A. Morales Moya (dir.), 2014, pp. 45-69, p. 46.

${ }^{4}$ Cfr. Luis Ribot, "El dictamen 'más firme a la seguridad de mantener inseparables los reinos de mi corona'. La sucesión de Carlos II", en A. Morales Moya (dir.), 2014, pp. 21 43, esp. nota 21. Si con este testamento Carlos II quería buscar una alianza honesta y fructífera con Francia, no lo consiguió. Si pretendía garantizar que las posesiones de su corona no se dividieran o integraran en otro Imperio, tampoco lo logró: España perdió todas las posesiones en Europa además de Menorca y Gibraltar, aunque luego Felipe $V$ recuperaría Menorca, Nápoles y Sicilia.
} 
los reinos de Escocia e Inglaterra se unían, a través de un acuerdo con naturaleza de Tratado internacional, bajo la soberanía de un único parlamento: el británico. Por virtud de dicho "Acuerdo", Escocia dejaba de ser reino, renunciaba a su parlamento y se integraba en el Reino Unido y en el Parlamento británico con sede en Londres. Precisamente el "common law" británico es lo opuesto a privilegios y derechos sectoriales o de base territorial. Pero es más, en aquella época no había democracia ni parlamentarismo digno de tal nombre en ningún país. En Cataluña, sin ir más lejos, los que estaban representados en sus Cortes eran las diversas oligarquías de la época, de forma muy similar al del bajo medievo. El parlamentarismo es lo que hoy sí existe en Cataluña y en toda España. ¿Dónde está la pérdida? Y si tan brillante era la receta británica de parlamentarismo, ¿̇cómo cabe entender que todavía hoy Escocia tenga menos poder que Cataluña? 5

Contra la propaganda separatista de una pretendida modernidad (si puede hablarse de tal en 1714!!!) robada por los borbones, en realidad, las cifras económicas se imponen a las dudas metafísicas: a Cataluña le vinieron bien los decretos de Nueva Planta. Como ha demostrado el economista e historiador Gabriel Tortella, Cataluña experimentó un crecimiento espectacular gracias precisamente a las políticas de los borbones, llegando incluso a doblar su población de 1718 (407.000) a 1800 (900.000).6 En esta misma línea el historiador catalán Vicens Vives reconoció que las instituciones suprimidas entre 1707 y 1716 tenían un carácter arcaico por lo que el "desescombro de fueros y privilegios" benefició "insospechadamente" a Cataluña.

Destaca igualmente la creación pro los borbones de una fiscalidad equitativa, moderna y muy llevadera. El catastro -que se implantó entonces por primera vez en Cataluña-supuso disponer de un sistema fiscal más moderno, justo y eficaz, que nunca llevó a tener que pagar muchos impuestos. Muchos menos en todo caso que la esquilmada Castilla, en la que sin embargo siguió de forma injusta incrementándose la presión fiscal sobre todo a partir de la segunda mitad del siglo XVIII. Su aportación a la Real Hacienda, que ya era entonces la mayor de España, se incrementó en un $85 \%$ del año 30 al 70, mientras que la de Cataluña, que partía de cuantías muy bajas, aumentó sólo en un 35\%. Por tanto, fue Castilla la que realmente salió perdedora del proceso, al menos en términos económicos y fiscales que son los que cuentan.

Otros elementos favorables al desarrollo de Cataluña fueron: la casi total abolición de las aduanas que hasta entonces la habían separado de las

\footnotetext{
5 Ver S. Muñoz Machado, 2014, pp. 17 ss, ver también Francesc de Carreras, "El año 1714 desde la perspectiva política actual", en A. Morales (ed), 2005, p. 449-465, pp. 454, 455. 6 "La renovación económica y social de los Borbones: la política económica de España en el siglo XVIII" en A. Morales (2014), pp. 263-291; con Clara Eugenia Núñez, "Más de quinientos años juntos: síntesis de la evolución histórica de Cataluña y el País Vasco en España" en G. Ibáñez y Marcos Allo (2014) pp. 65-92
} 
tierras del sur del Ebro, la protección arancelaria de su industria, el estímulo de los intercambios de Cataluña con América (La Casa de Comercio de Barcelona se crea en 1755) y el comercio libre sobre todo a partir de 1745; es decir, el acceso total a los mercados del resto de España y América. Algo probablemente que no hubiera permitido la "pretendidamente muy catalanista" Inglaterra, de haber vencido en la Guerra de Sucesión, ya que sus productos competían con los catalanes y aspiraba a una posición dominante en el comercio con América. Pero esto también se oculta.

El propio Rafael Casanovas, hoy alabado hasta la extenuación como un héroe "nacional-catalán" no le vio sentido a la resistencia, se opuso a los líderes de la misma y murió totalmente desengañado. Otro héroe falsificado.

\section{6. ¿Dónde estaban los nacionalistas catalanes durante los siglos XVIII y $\mathrm{XIX}$ ?}

En ninguna parte. En la guerra de 1808-1812 contra la invasión napoleónica, todos éramos independentistas..., "españoles", salvo los "afrancesados". En la famosa batalla del tambor del Bruc, los catalanes ayudados por tropas suizas, se levantaron en armas contra la invasión francesa que estaba causando estragos económicos y físicos en la población. ¿¿Defendían la singularidad catalana? No, defendían a España entera uniéndose a la revuelta que un mes antes había prendido en Madrid. Y en las discusiones que tuvieron lugar para elaborar la Constitución de Cádiz, tres de los diputados más firmemente defensores de la unidad de España fueron los catalanes Antonio Capmany, Espiga y Gadea y Ramón Lázaro de Dou y de Bassols. Este último fue además el primer presidente de las cortes de Cádiz. De los diecisiete diputados catalanes solo Josep Rius defendió los fueros particulares y de forma bastante moderada.

En 1859, medio millar de voluntarios catalanes participaron en la guerra contra Marruecos, bajo las órdenes de un joven general Prim, catalán, en la célebre batalla de Wad-Ras, bajo la arenga de que debían hacer honores al ejército "del bravo O'Donnell, que ha resucitado a España y reverdecido los laureles patrios". Por cierto que de no haber sido asesinado Prim (en una muerte todavía por resolver), entonces presidente del gobierno español, la historia del nacionalismo habría sido probablemente otra.

En la I República, Cataluña no reclama para sí un trato singular o diferente al del resto de regiones españolas en la nueva Federación. De hecho, dos de los presidentes de la I Republica serán catalanes (Figueras y Pi i Margall). Por cierto, que "el café para todos" nace aquí, no en 1978.

En el siglo XIX las reclamaciones catalanas no pasaron de defender sU derecho civil propio o lamentarse del predominio de castellanos en 
cargos públicos, a pesar de que hemos visto que varios presidentes fueron catalanes. La política de conceder privilegios a la burguesía catalana se hizo estructural por parte de los distintos gobiernos de Madrid, incluso durante el franquismo. Como resultado, a principios del siglo XXI (según INE), la renta por habitante de Cataluña era un $21,8 \%$ superior a la media española. Mientras, el resultado de separarse de España y caer bajo la protección británica que siguió Portugal a partir de 1640 se concretó en que en el mismo periodo su renta por habitante llegó a ser un $24,8 \%$ inferior a la media española (según Banco Mundial). Por no hablar de la misma Francia, donde ta renta de los habitantes del Languedoc-Rousillon, Provence-Alpes-Côfe d'Azur y Córcega..., es bastante inferior a la de los catalanes del "Espanya ens roba".

\section{7. ¿Cómo y por qué resurge el nacionalismo catalán en el siglo XX?}

El nacionalismo catalán solo "resurgirá" muy a finales del siglo XIX. El propio Cambó (1876-1947), líder de la "Liga Regionalista", reconocería en sus memorias que todavía en primavera de 1883 el nacionalismo catalán era "una cosa mísera". ¿Por qué entonces esa reacción nacionalista? Hay varias posibles explicaciones, pero una de las que suele esconderse fue la siguiente: Cataluña venía imponiendo una política defensivaproteccionista al resto de España para sus productos. Esa política se basaba en un arancel muy alto para los productos que venían de fuera y que podían competir interna y externamente con los producidos en Cataluña. Aunque la incidencia en su comercio era limitada, Reino Unido se quejó formal y reiteradamente ante los distintos gobiernos españoles. Fruto de esas presiones, el gobierno español acabó aceptando bajar los aranceles a los productos británicos y apostar por el librecambismo. Esta decisión causó la primera reacción, que podemos considerar "nacionalista", de la burguesía catalana desde hacía más de ¡170 años!

Valentí Almirall, que durante la I República había defendido la vertebración de Cataluña dentro España desde el respeto absoluto y el plano de igualdad entre aquélla y el resto de estados federales españoles, empezó a cambiar de criterio y a reclamar un trato singular para Cataluña. Aun así, todavía en 1886 publicaba "'España tal como es", diciendo que los catalanes son tan españoles como el resto de habitantes de las demás "regiones" de España; así las llamaba, ni naciones, ni estados, ni comunidades autónomas... Posteriormente, el cambio radical en la tendencia de casi dos siglos se plasmaría en las "Bases de Manresa" de 1892 (redactadas por cierto sólo en tres días, lo que da muestra de la "seriedad" del proceso) y sobre todo en La nacionalitat catalana de Enric Prat de la Riba (1906), otro de los "héroes" del separatismo. Y sin embargo ¿̇quién propuso "Por Cataluña en una Gran España"?, ¿̇Tal vez algún traidor a la patria catalana? Pues no, fue el mismo Prat de la Riba, en las elecciones de 1916 como alternativa al separatismo. Por cierto, su maestro Eugenio D'Ors, también catalán y de 
mayor nivel intelectual que Prat, acabaría siendo Jefe Nacional de Bellas Artes durante el franquismo.

Pero la fecha que lo cambió todo fue 1898. España pierde Cuba, Filipinas y Puerto Rico, y, como consecuencia, la burguesía catalana siente como propia la pérdida de dos islas que eran en realidad colonias comerciales suyas. De hecho, paradójicamente gran parte del descontento cubano y filipino con España se debía precisamente a los privilegios comerciales catalanes. Es de esta época cuando surge la bandera de la "futura" Cataluña independiente (la "estelada") creada por Albert Ballester en 1908 siguiendo el ejemplo de las banderas cubana, filipina y de Puerto Rico. De esta manera se reconocía implícitamente que la bandera tradicional fla "senyera" que coincide con la aragonesa) no representaba a ninguna nación histórica y soberana.

El nacionalismo lograría su máximo apogeo con la II República, aunque paradójicamente acabaría traicionándola. Aun así las peticiones del nacionalismo catalán no irán mucho más allá de la consagración de una cierta autonomía, reconocida por la II República, quien proclamaría el Estado integral, permitiendo al mismo tiempo aprobar el primer Estatuto de autonomía catalán (1932). Desde el principio, Esquerra Republicana de Cataluña (entonces no existía Convergencia) contó con ministros en los gobiernos de Madrid: Jaume Carner fue ministro de Hacienda y el propio Lluis Comanys iiiministro de marina!!!. ¿ Sirvió esto para contentar al nacionalismo? Pues no. El 6 de octubre de 1934, Lluis Companys declaraba el Estado catalán.

Durante el franquismo entra en una época de moderación y silencio reivindicativo, no sólo a causa de la represión franquista. De hecho, la mayor resistencia al franquismo procederá de otras regiones, incluida la propia Madrid. Tal vez influyó en ello que, de nuevo, cuando más centralista era el gobierno de Madrid mejor le iba especialmente a la economía de Cataluña.

Con la llegada de la democracia y La Constitución de 1978, parecía que se iba por fin a encontrar una solución equilibrada que contentara a todos. Cataluña cuenta hoy con un Estatuto de Autonomía política y económica mucho más ambicioso que el de la ll República (el cual por ejemplo no cedía la competencia de educación). Pero mientras unos renunciaron ingenuamente al centralismo, a cambio de la concordia, los presuntos nacionalistas moderados prepararan en secreto un plan para romper España. ¿̇Cómo justificar la legitimidad de un derecho a la secesión en pleno siglo XXI dentro de un Estado europeo consolidad? Es cuando aparece el "derecho a decidir" y resurge la leyenda de España como Estado autoritario. 


\section{8. ¿Una España franquista y primitiva versus una Cataluña democrática y moderna?}

Aquí la manipulación alcanza probablemente sus mayores cotas de sofisticación. Todo vale, se mezclan churros con zanahorias sin rubor alguno. Lo único que importa es hacer creíble un cuadro donde unos pobres e inocentes ciudadanos tratan humildemente de votar mientras un oscuro Estado español, todavía franquista e inquisitorial, se lo impide y encarcela injustamente a sus líderes. Para ello resulta imprescindible defender que el franquismo sería una enfermedad incurable, presente en amplios sectores de la sociedad española de hoy, lo que supone indirectamente cuestionar el éxito y la reconciliación que supuso la Transición política tras la muerte de Franco.

Da igual que este enfoque no se dé donde ha gobernado el fascismo (Italia), el nazismo (Alemania) o el comunismo (toda la Europa del Este), incluso con millones de muertos. Da igual que la monarquía haya sido refrendada en 1977 y en 1978. Da igual que el ejército español sea considerado hoy un ejemplo a seguir en la OTAN y en las operaciones de la UE. Da igual que tengamos una de las Constituciones más protectoras de los derechos humanos y una de las pocas que reconoce expresamente (art. 10.2) a la Declaración Universal de Derechos Humanos o a la Convención Europea como baremo interpretativo. Da igual que en el año 2017 España sólo recibiera 6 condenas del Tribunal Europeo de Derechos Humanos frente a las 10 de Suiza, 12 de Francia, 16 de Alemania ó 31 de Italia. Da igual que España se encuentre entre las 20 naciones más democráticas del mundo según las principales clasificaciones internacionales.

Todo eso da igual. La leyenda áurea es lo que importa. Cataluña habría contado con un "parlamento" desde 1218, mientras España (como si fuera algo separado) sólo lo crearía en 1834. En realidad, los primeros parlamentos del mundo son el Althing de Islandia y las Cortes de León (1188). Todo lo primitivos que se quieran pero es ahí cuando comienza la tendencia a crear cámaras representativas de la población, sin olvidarnos de la importancia que jugaban los Concilios en el reino visigodo, que carecía de un sistema hereditario.7 Con la convocatoria efectuada por Alfonso IX de las Cortes de León se produce la primera Asamblea de carácter popular tras el Imperio romano en Europa

\footnotetext{
7 Lo reyes godos no ejercían un poder absoluto, sino que dependían para muchas decisiones de los Concilios, una suerte de primigenio sistema de "cheks and balances". La importancia del Concilio como antecesor del Parlamento no ha sido apenas destacada. Otro aspecto positivo del régimen visigodo era el peso de que gozaban la ley, de la tradición y de los juramentos. Cierto que el rey era quien emitía las leyes y ejercía de juez supremo, pero ese poder para ser ejercido en la práctica dependía de pactos con otras élites y una red de jueces más o menos profesionalizados [ver sobre el funcionamiento del sistema legal en esa época: Pablo Poveda Arias, "Relectura de la supuesta crisis del fin del reino visigodo de Toledo: una aproximación al reinado de Egica a través de sus fuentes legales, AHDE, 2015, tomo LXXXV, pp. 13-46].
} 
continental. Otras "Cortes" empezarán a proliferar por todo el territorio español, donde se representaban diversos estamentos (nobleza y clero), pero también a las ciudades, lo que era revolucionario para la época. Precisamente en Cataluña se las llama, por imitación, "les corts", siendo por tanto posteriores a las de León.

Para perfilar ese diseño sesgado de una España tenebrosa se ocultan igualmente personajes, por ejemplo, como san Isidoro de Sevilla (560-636) quien planteó por primera vez una definición de ley que incluía el consentimiento de sus destinatarios, o aportaciones de la Escuela de Salamanca (desde Francisco de Vitoria, Domingo de Soto, Luis e Molina a Juan de Mariana) que en pleno siglo XVI introdujo los derechos subjetivos (a la vida, la libertad, al propiedad y la igualdad de trato ante la ley), el derecho internacional, la legitimación en el uso de la fuerza, la importancia del gobierno limitado, la lucha contra los gobernantes corruptos (llegando incluso en ciertos casos a justificar el tiranicidio), y el principio de consentimiento de los ciudadanos en caso de cambios de leyes, aumentos de impuestos o alteración de la moneda. De hecho, la pálabra "liberal" tiene su origen en la lengua española.

Del pasado remoto pasamos al pasado reciente. Siglo XX. Los separatistas catalanes se presentan como defensores de la libertad, la democracia y la república frente a la España absolutista que habría apostado por un régimen totalitario como el franquismo aliándose con las potencias del Eje. Para que este cuadro sea vendible se requiere ocultar o manipular algunos hechos históricos muy relevantes:

-fue el catalanismo político (la Lliga Regionalista) quien en septiembre 1923 promovió, organizó y apoyó la primera dictadura militar de España encabezada por el general Miguel Primo de Rivera.

-el nacionalismo catalán traicionó la legalidad republicana. Lo hizo primero en 1934, estando en el gobierno de Madrid el catalán Alejandro Lerroux, al decidir proclamar de forma ilegal y unilateral la República catalana. El presidente de la Generalitat Lluis Companys fúe detenido, junto al resto de su gobierno, por el general (también catalán) Domingo Batet. Se suspendió la autonomía y el Tribunal de Garantías Constitucionales los condenó por rebelión. Pero pocos días después de las elecciones de 1936, el gobierno del Frente Popular (una alianza de radicales republicanos, socialistas y comunistas) aprobó un decreto-ley de amnistía, restaurando al mismo tiempo la autonomía ¿̇irvió esto para asegurar la fidelidad del nacionalismo la República y sus leyes? Pues no. El propio Companys, héroe (redecorado) de los separatistas, persiguió a los catalanes católicos y fue responsable de más de 8.000 ejecuciones de catalanes, la mayoría sin juicio previo. Prohibió todo festejo relacionado con la Navidad, y fusiló al alcalde de Lérida, Joan Rovira Roure, de la 
"Lliga catalana", por el terrible cargo de organizar una cabalgata de reyes.

-pero el nacionalismo también traicionó a la República durante la Guerra Civil. De hecho, Franco ganó una guerra que tenía en un principio perdida, entre otros factores, gracias a la traición del nacionalismo vasco (que pactó con los fascistas italianos) y al apoyo financiero y propagandístico que recibió del nacionalismo conservador catalán: desde Cambó, hasta Ventosa y Bertrán y Güett. Pero a ello se unió que los nacionalistas catalanes pretendían hacer la guerra por su parte. De hecho, el último presidente del gobierno republicano, Juan Negrín, llegó a manifestar que no dudaría en ponerse: "a gritar en la plaza de Cataluña que si la guerra se pierde, se perdería principalmente por la conducta insensata y egoísta de Cataluña" (cfr. J. Zugazagoitia, 1968, p. 44) Y el último presidente de la República, y uno de los mayores defensores del primer Estatuto de autonomía catalán, Manuel Azaña, compartiría ese diagnóstico afirmado por boca de su alter ego Garcés en La Velada de Benicarló (1981, p. 141) que "(...) A este paso, si ganamos, el resultado será que el Estado le deba dinero a Cataluña (..) Cataluña ha sustraído una fuerza enorme a la resistencia contra los rebeldes y al empuje militar de la República".

-también se olvidan los lazos y contactos que hubo desde muy pronto entre un sector del nacionalismo catalán y el nazismo alemán. Ya antes de la toma del poder del Partido Nazi, en 1933, el grupo Nosaltres Sols! sondeó un posible apoyo nazi para su causa. En junio de 1935, el líder del grupo (se dice que Manuel Blasi) viajó a Alemania para entregar un memorándum al Ministerio de Propaganda del III Reich, donde contemplaba las posibles ventajas mutuas de una colaboración activa entre Alemania y el separatismo catalán. Este grupo venía defendiendo la superioridad racial de los catalanes sobre los "africanos" españoles. Por su parte, el partido ERC (el mismo al que pertenecen varios de los hoy encarcelados) organizó y mantuvo unas milicias juveniles, los "escamots" como "fuerza de choque" a semejanza de los camisas negras italianos, que desfilaban con uniformes miliares, y que protagonizarían numerosos episodios de violencia extrema, en particular contra anarquistas, apoyando por otra parte a la patronal contra los huelguistas. Detrás se encontraban los hermanos Badia (Miquel y José) y Josep Dencás (éste muy cercano al fascismo italiano), a los que se considera creadores del "fascismo catalán".8

\footnotetext{
8 Miquel Badia, miembro del partido Estat Catalá, fue nombrado por Lluis Companys Jefe Superior de Policía de la Generalitat de Cataluña. Pero cuando Companys se enamoró de Carme Ballester (amante de Badía) y se casó con ella, lo cesó. Miquel Badía acabaría asesinado en Barcelona el 28 de Abril de 1936 en una muerte todavía
} 
Algunos podrían defender que todo esto pertenece al pasado, que hoy el separatismo catalán defiende la libertad y los derechos civiles: pero esto también dista de ser cierto. Por de pronto, los hermanos Badia soy hoy idolatrados tanto por el presidente Quim Torra como por Oriol Junqueras, como héroes de la construcción nacional. El nacionalismo catalán sigue siendo una ideología de base supremacista que busca romper con argumentos arteros una comunidad política que venía conviviendo y funcionando desde hace siglos. Ciertamente no era así todo el nacionalismo, pero sí el sector que ha acabado imponiéndose y liderándolo.

Esta peligrosa deriva ya fue denunciada por el último presidente de la Generalitat en el exilio, Josep Tarradellas (curiosamente del mismo partido ERC, que el encarcelado Oriol Junqueras!), en 1980 cuando volvió a España. Tarradellas se manifestó contrario al nacionalismo radical y a cualquier veleidad separatista, alertando que las verdaderas intenciones de Jordi Pujol (presidente del gobierno catalán desde 1980 a 2003) que pasaban por traicionar el pacto constitucional de reconciliación que supuso la Constitución democrática de 1978 ("Se liará en la estelada y se hará víctima de Madrid"). Nadie le hizo caso, pero de hecho, a pesar de haber obtenido el Estatuto de autonomía más amplio de su historia, Pujol diseñó un plan (Programa 2000) para catalanizar la sociedad en todos los sectores, empezando por la educación, aunque ello supusiera discriminar a más de la mitad de la población.

El plan requería un proceso de ingeniería social bajo una pátina democrática para hacerla vendible al mundo, presentando a los independentistas como víctimas y al resto como verdugos cuando la realidad era justa la contrario. Es aquí donde aparece el mantra político del "derecho a decidir", en realidad una mera trampa emocional e ideológica para esconder otros debates más incómodos (como el de la realidad/falsedad del paraíso post-independencia), al tiempo que se confunde como un presunto derecho a la autodeterminación de los pueblos reconocido por la ONU, cuando las Resoluciones de la Asamblea General de ta ONU no 1514 (1960) y nº 2625 (1970) limitan el derecho a la autodeterminación a los casos de dominio colonial y notoría violación de derechos humanos.

Pero es que tampoco resulta muy democrático que el derecho a decidir de unos cuantos (los que la Generalitat decida que son catalanes) impida el derecho a decidir de la mayoría (el resto de los españoles) sobre lo que debe ser su país: España. De hecho, un país mucho más

por resolver. No fueron en todo caso los franquistas sino probablemente un comando anarquista encabezado por Justo Bueno, pero que actuaba por cuenta de un tercero. Una pista la dió Josep Andreu (presidente de la Audiencia Territorial de Barcelona) quien declaró que ese mismo día, Badía le iba a entregar un dossier contra Companys. Muerto Badia del dossier nunca más se supo. Cui prodest? 
moderno que España (los EEUU) ya estableció en 1869 a través de sU Tribunal Supremo (Texas $v$. White) que la unión nacional no es una suerte de liga disoluble al capricho o conveniencia de una de las partes.

Pero es más, en realidad dicho derecho a decidir ya se ha ejercido, incluso bajo la "terrible" legislación española: las elecciones autonómicas del 27 de septiembre de 2015 fueron planteadas por los propios separatistas como un plebiscito (legal) sobre el independentismo. Acabado el recuento, la propia CUP (partido radical separatista) reconoció públicamente que lo habían perdido. De hecho, por esta razón (entre otras) dimitió su principal dirigente de entonces, Antonio Baños, quien señaló: "en ningún país del mundo puedes decir que con el $48 \%$ has ganado, no puedes ir a ningún lado, pierdes el plebiscito". Por tanto, en férminos estrictamente democráticos, tras haber perdido el plebiscito legal del 2015: a) no hacía falta convocar más referéndums (mucho menos sin las mismas garantías) y b) todo lo que ocurre después (leyes de desconexión) podría ser legal, pero ya no "estrictamente" democrático, pues se estaba legislando contra el sentir mayoritario de púeblo.

El principio básico del separatismo no es el democrático sino el maquiavélico de que "el fin (conseguir la ruptura de España) justifica los/cualquiera medios". La democracia no es sino un medio más (solo en la medida que resulte útil), como lo es la propia ley (sean catalanas o españolas) o llegado el caso incluso el propio Tribunal Constitucional. Que el separatismo ha utilizado los jueces y la ley (aunque sean españoles), mucho más que la democracia, se demuestra por de pronto en que Cataluña es la única Comunidad Autónoma que no cuenta con ley electoral propia. ¿̇Por qué? Porque en esta ocasión mantener una norma estatal favorece, injustamente, a los partidos independentistas. En el Parlament, se escogen 135 diputados: 85 por Barcelona, 18 por Tarragona, 17 por Gerona y 15 por Lérida. Un escaño en Barcelona cuesta más de 48.000 votos, mientras que en Lérida sólo unos 21.000. Dado que en Barcelona (de mayoría constitucionalista) vive más del $72 \%$ de la población catalana, las otras tres circunscripciones aparecen claramente sobrerrepresentadas. Todo ello, por no hablar del adoctrinamiento en las escuelas o el uso torticero de los medios de comunicación subvencionados por la Generalitat.

Por lo tanto, el nacionalismo nunca ha sido democrático por convicción, sino más bien como un medio (interesado) para un fin. Por el contrario siempre ha tenido una base racista y supremacista que le llevó a conectar en su día con el fascismo italiano y el nazismo alemán, algo que hoy no solo no ha desaparecido sino que se ha acrecentado, al manifestarse en una estrategia sectaria mantenida en el tiempo, y con amplios recursos, de presión constante hacia los ciudadanos que no se sienten separatistas: las verdaderas víctimas del proceso. Aunque no hay cifras oficiales, el número de personas que han decidido abandonar 
Cataluña desde que gobierna el nacionalismo superaría ya al número de catalanes que fue al exilio tras la guerra civil. En este sentido, aunque no se disponen de datos oficiales, diversos estudios cifran el exilio permanente de españoles como consecuencia de la guerra civil entre 200.000 (cfr. Bartolomé Bennassar o Jordi Rubió Coromina) y 500.000 personas, de las que (tomando esta última cifra), 50.000 serían vascos. ${ }^{9}$ Pues bien de acuerdo con un Informe elaborado en 2007 por la Fundación BBVA (Evolución de la población española en el siglo XX) casi 200.000 personas habrían abandonado el País Vasco desde que ETA inició su actividad terrorista (un $10 \%$ de la población). Y no parece que hayan vuelto o que el fenómeno haya desaparecido tras el fin de la "Iucha armada". En cuanto a Cataluña, es difícil encontrar cifras oficiales de la cantidad de personas que han abandonado Cataluña desde que gobierna el nacionalismo, aunque parece que este proceso se está acelerándo. En 2017 la empresa SocioMétrica realizó una encuesta que daba el siguiente dato: el 14\% se marcharía de Cataluña si se proclamase la independencia, algo más de un millón de personas. ${ }^{10}$ ¿ Quién protege a estos ciudadanos?

\section{9. ¿Es el español una lengua "extranjera" e "impuesta" en Cataluña?}

¿Qué razones de peso habría por tanto para sostener una singularidad digna de un trato especial y "soberano" para Cataluña? Pues sólo quedaría la lengua. Pero ¿es la lengua causa suficiente para crear una identidad independiente? En la India sobreviven alrededor de cien lenguas y no hay grandes reivindicaciones secesionistas, mientras existen veinte países diferentes que comparten el idioma español como lengua oficial. Para que la lengua pase de mero instrumento de comunicación a causa identitaria se necesitan al menos otros tres condimentos: el complejo, el agravio y una lengua enemiga. Un triángulo vicioso que se retroalimenta de forma perversa.

El complejo puede ser tanto de inferioridad (sentirse una comunidad lingüística en peligro de desaparecer) como de superioridad (el catalán es lengua superior y más antigua que el resto). El agravio simplemente requiere mantener un sentimiento de persecución permanente por hablar esa lengua. Y żquiénes la perseguirían? Pues los que hablan otra lengua que quieren acabar con la suya. La realidad sin embargo no es como la pintan los separatistas

En todas las naciones europeas se hablan diversas lenguas, algunas de ellas anteriores al catalán o al gallego (González-Varas, 2002, pp. 84189).Tras la caída del imperio romano el latín fue transformándose dando lugar a distintas lenguas romances. Unas perduraron y otras no (e.g. el

\footnotetext{
9 Ver Jesús J. Alonso Carballés. "El primer exilio de los vascos, 1936-1939", Historia Contemporánea, $n^{\circ} 35,2007,683-708$

10 https://cronicaglobal.elespanol.com/politica-de-cookies.html
} 
aragonés). El ibero-romance siempre se ha hablado en Cataluña, la cual ha tenido por así decirlo una doble alma lingüística. Lo que ha variado, en función de la época, es cuál de las dos lenguas predominaba o era utilizada más por las élites o por las clases populares, no siendo siempre la misma. De hecho, el "castellano" siempre ha sido una lengua franca en la que se entendían todos los habitantes de España (e incluso del extranjero), razón por la que fue conocida desde muy pronto como "español". Cuando en la transición política se convirtió (falsamente) en un problema la denominación de la lengua común, los primeros sorprendidos fueron (y siguen siendo) todos los que hablaban, y venían hablando, el español fuera de nuestras fronteras. Tendemos a olvidar que esta lengua nos une no solo a los españoles sino a una comunidad de más de veinte naciones y 470 millones de personas; por lo tanto no nos pertenece en exclusiva y en consecuencia no podemos cambiar su nombre a capricho de algunos.

Pero lo de crear una lengua franca no fue un capricho español. A partir del siglo XVII todas las naciones europeas optaron por privilegiar y consolidar un idioma común como único modo de construir un Estado moderno y competir económicamente. España no fue por tanto una excepción, y figuras de la talla del valenciano Gregorio Mayans y el catalán Josep Pau Ballot y Torres (que publicó una gramática catalana en 1814) así lo advirtieron (Orígenes de la lengua española, 1737). En nuestro caso esa estrategia aparecía reforzada por la presencia masiva del español en tierras americanas. Esta visión que respondía al puro sentido común fue compartida por Cataluña y el País Vasco, al menos hasta mediados del siglo XIX;11 e incluso del XX, si recuperamos el debate parlamentario que dio lugar al art. 50 de la Constitución de la ll República, en una enmienda defendida por Claudio Sánchez Albornoz y firmada por diputados vascos y catalanes, entre ellos el mismo Lluis Companys.

Por tanto, el castellano acabó imponiéndose por la fuerza... de los hechos, sin que el gobierno español hiciera "esfuerzos" similares a los de otros países por imponerlo. A lo más que se llegó fue tal vez a la célebre Instrucción de 1716 (tras la guerra civil y dinástica de 1715), citada a menudo como ejemplo de agravio desde el mundo nacionalista, digida a los corregidores de Cataluña que señalaba lo siguiente: "Pondrá el mayor cuidado en introducir la lengua Castellana, a cuyo fin dará las providencias más templadas, y disimuladas para que se consiga el efecto sin que se note el cuidado".

En todo caso, se oculta que el español se habló antes en el valle el Ebro que en el del Tajo, a pesar de que los primeros libros publicados en letra impresa en España habían sido en valenciano —en aquella época no había una gramática catalana que claramente se impusiera a la valenciana-, simplemente porque fue en Valencia donde se instaló la

11 Ver: Joaquín Álvarez Barrientos, "Cultura e llustración. Interpretaciones catalanas del siglo XVIII" en A. Morales (ed.), 2014, pp. 293-313, p. 303. 
primera imprenta en España en 1474. Allí se publicaron obras de Joano† Martorell (1413-1468), como el famosísimo Tirant Lo Blanch, o de Ausiàs March (1397-1459). Aquí no se prohibió ninguna lengua, a diferencia de lo que ocurrió en países presuntamente más modernos y democráticos. En 1539, Francisco I, rey de Francia, promulgó en la ciudad de VillersCorretêts una ordenanza que establecía el francés como la lengua única de los documentos oficiales, desterrando de la administración idiomas como el provenzal, el bretón o el occitano. De hecho, Luis XIV prohibió el uso del catalán en los terrenos anexionados por Francia tras la rebelión catalana de 1640. Y en el Acta de Unión de Gales e Inglaterra, de 1531, se eliminó el galés y el gaélico de los tribunales de justicia. Mientras, en nuestro país, de las treinta universidades con que contaba España en Europa (24) y en América (6) ofrecían en pleno siglo XVI libre elección de lengua, algo insólito para la época.

Si los reyes españoles hubieran perseguido realmente el catalán (y tuvieron siglos para hacerlo) éste probablemente habría desaparecido. Por eso ha sobrevivido..., en España porque el catalán en la Cataluña francesa o las zonas de Italia de pasado catalán, solo sobrevive allí a duras penas, gracias singularmente a las ayudas económicas que ofrece la propia Generalitat.

No ha habido imposición del español, al menos no mayor que la imposición del catalán. En este sentido, por ejemplo, al tiempo que la Iglesia mantenía sin controversia la utilización de una lengua "común" muerta como el latín, en 1727 los prelados catalanes dispusieron que no se permitiera explicar el evangelio en otra lengua que no fuera la catalana. El papel jugado por la Iglesia también se olvida. En todo caso, hoy, si hay una lengua perseguida es el español El presidente de la Generalitat Quim Torra ha llamado "bestias taradas" a los catalanes que hablan español y en el marco del aniversario del 1 de octubre del año anterior incitó a los secesionistas a "apretar" para lograr imponer su voluntad. Por no hablar de las instrucciones que reciben las escuelas. Cataluña es junto a Groenlandia las dos únicas regiones europeas donde no se permite que la lengua común del Estado sea lengua vehicular de la educación, aunque en este caso se trate de la lengua materna de más de la mitad de los catalanes y la segunda lengua más hablada del mundo. ¿̇Quién protege los derechos de estos niños?

\section{0. ¿Son los catalanes una raza diferente?}

Puede que alguno se sorprenda de esta pregunta, pero es una tesis que no solo se ha defendido en el pasado (recuérdese la posición de Nosaltres Sols! en 1935 sobre el origen africano de los españoles) sino muy recientemente. Oriol Junqueras, líder de ERC, en un artículo publicado el 27 de agosto de 2008 en el diario 'Avui' sostenía que "los catalanes tienen más proximidad genética con los franceses que con los españoles; más con los italianos que con los portugueses; y un poco con los suizos... [solo]

EMUI_EuroMed University | ISSN 1578-6730 · Nomads. Mediterranean Perspectives | ISSN 1889-723] (C) 1999, Román Reyes, Fundador y Director · (c) 2016, Progetto Pier Paolo Pasolini 
hay tres Estados, donde ha sido imposible agrupar a toda la población en un único grupo genético. En Italia; en Alemania, siguiendo la vieja frontera lingüística entre el alemán marítimo y el continental; y en el Estado español, entre españoles y catalanes".

En realidad, estudios independientes en materia de genética de poblaciones muestran que España es un país bastante homogéneo, y que hay menos diferencia genética entre un vasco o catalán y un andaluz, que entre éste y un marroquí (ver A. Gómez Moreno, 2017, pp 145-159). La característica principal de España ha sido la mezcla de poblaciones (o mestizaje) no solo en Hispanoamérica sino dentro de la propia España. Tras la reconquista, Castilla y parte de Andalucía se quedaron prácticamente vacías y fueron repobladas por vascones y otras poblaciones del norte. Estos movimientos migratorios internos continuaron posteriormente prácticamente hasta nuestros días. Como resultado, en términos de ADN la genética hermana a un $85 \%$ de los vascos con un $66 \%$ de los manchegos. El haplogrupo diferencial del País Vasco (DF 27) está más presente en Zahara de los Atunes (Cádiz) que en Burdeos, capital de la Nueva Aquitania y no hay hermandad genética más estrecha que la que se da entre la mayoría de los gerundenses y habitantes del literal catalán de una parte, y los manchegos de otra; o la que se da entre un vasco y un mallorquín, por ejemplo

Pero es más, según Informe del Instituto Nacional de Estadística publicado el 22 de mayo de 2014, el apellido más frecuente en 2012 en las tres provincias vascas y en las cuatro catalanas era "García", lo mismo que en otras veintiocho provincias españolas, y los nombres más frecuentes tampoco parecían muy diferentes al resto de España. ${ }^{2}$ Mientras el apellido "España" tiene su origen en Cataluña, más concretamente en Lérida.

\section{Por último, ¿a quién beneficia que España se rompa?}

La España democrática ha sido, desde finales de los años 70 del siglo XX y a pesar de todas sus deficiencias, una historia de éxito. No hay más que mirar las cifras de crecimiento neto, de incremento de la renta per cápita, el Estado de bienestar, las grandes empresas o éxitos deportivos, o el mero proceso de transición pacífica de la dictadura a la democracia... Existen y han existido claros y oscuros, como en ta historia de cualquier otra nación, pero aspirar a que en una trayectoria histórica tan larga como ésta no aparezca ninguna sombra es muestra de la más exquisita ingenuidad. $\dot{\imath}$ Entonces? $\dot{\imath}$ Por qué romper este proyecto? Cui prodest? $\dot{\imath} \mathrm{A}$ quién beneficia un derecho a la secesión permanente?

Hace unos años se editó un libro colectivo titulado A favor de España: los costes de la ruptura, donde un grupo de expertos (por cierto incluidos un

12 http://www.ine.es/daco/daco42/nombyapel/nombyapel.htm 
buen número de vascos y catalanes) analizaban los costes de romper España desde variados enfoques y puntos de vista (económico, comercial, social, cultural, político, histórico...) llegando a una conclusión aplastante: resultaba contraproducente para todos. Por de pronto, si Cataluña y el País Vasco fueran regiones pobres, con todas las demás características de singularidad intactas, no defenderían lo que defienden. No reclamarían la autonomía fiscal ni soportarían que esta idea la proclamaran Extremadura y Andalucía, si estas fueran las más regiones ricas. Entonces "lo suyo" sería que estas últimas les transfieran más recursos utilizando para ello las excusas que fueran necesarias.

Y ¿̇por qué Cataluña y País Vasco son más ricas que el resto? Pues sin desmerecer sus méritos propios, no puede olvidarse que "algo" habrá tenido que ver que hayan sido favorecidas por inversiones y políticas "españolas" desde hace siglos: ¿̇dónde se situó la siderurgia? ¿̇por qué se aprobaron medias proteccionistas? Por no hablar del aporte en horas de trabajo baratas que ofrecieron precisamente andaluces y extremeños, trabajadores de sol a sol, a los que ahora se pretende despreciar y obligar a romper con sus familias.

¿Le interesa a Europa? Si los separatistas son incapaces de convivir con el resto de españoles, como vienen haciendo desde hace siglos, ¿̇con qué legitimidad podrá creérseles cuando dicen que lo harán sin problemas con el resto de europeos? Además, destruir antiguos Estados existentes por el hecho de contener diversas minorías etno-religiosas, resulta además contradictorio con la defensa, como virtudes cívicas, de los principios de pluralidad, multiculturalidad y respeto por "los diferentes". Si se permite que Estados-nación con más de 500 años se rompan en un puzzle de nuevos/viejos reinos de taifas de indeterminada y costosa digestión, la propia UE con poco más de 60 años a cuestas sería la siguiente en disolverse como un azucarillo. ${ }^{13}$

¿ Le conviene a la paz y seguridad globales? La Comunidad internacional no debería permanecer impasible o ciega ante el fenómeno del nacionalismo disgregador -incluso en términos morales o éticos- pues éste persigue la destrucción de viejas naciones exacerbando lo que separa y defendiendo el supremacismo de unas culturas sobre otras. El nacionalismo se aprovecha de la necesidad imperiosa de todo ser humano de identidad, sentido y objetivos, ante el vacío existencial actual y la crisis de las religiones e ideologías. Pero pretende colmar estas demandas -en lugar de alentando el sentimiento de cohesión y solidaridad o la mejora de la calidad de vida de todos los ciudadanos, como haría un sano patriotismo- de manera simplista: uniendo a unos (los "suyos") contra "los otros" (los "no-nacionalistas"). Supone lo contrario

13 G. Ibáñez, Alberto "Si se rompe España, se rompe Europa" [https://www.vozpopuli.com/opinion/rompe-Espana-Europa-independentismocataluna_0_1158184515.html] 
al enfoque multicultural pues trata de expulsar o hacer la vida imposible al culturalmente discrepante, aunque lleve viviendo allí tantos años o más que el nacionalista supremacista.

De los 194 Estados existentes en la actualidad, más de 150 incluyen importantes minorías religiosas y étnicas. ¿¿Queremos romperlos? Si admitimos como deseable que las naciones deban ser cultural y étnicamente homogéneas, deberemos prepararnos para llegar al menos a 5.000 Estados independientes, el número de grupos étnicos que identifica el Informe sobre Desarrollo Humano de la ONU (2004). De los 193 Estados reconocidos por la ONU (más el Vaticano), el $85 \%$ tienen una composición multiétnica. O żpreferimos sucumbir al dulce canto de sirena de que cada comunidad lingüística (como sería la catalana) requiere contar con su propio Estado? Según los criterios elegidos, en la actualidad existen entre 3.000 y 5.000 lenguas reconocidas como tales en el mundo (además de las lenguas que por razones políticas son tenidas como dialectos, por ejemplo en Italia), mientras que habría que unificar todos los actuales Estados independientes que comparten un mismo idioma. ¿̇Es abrir este melón lo que necesita un mundo crecientemente globalizado?

"El nacionalismo es un estado de ánimo" (S. de Madariaga, 1979, p. 187) y como tal susceptible de ser creado artificialmente y también de desaparecer. Un estado emocional que se crea, crece y se exacerba en torno a un doble instrumento: el fomento del odio y la creencia de la superioridad del nacionalista frente a un tercero ("el otro"). Este tercero puede ser distinto en cada caso según toque: el extranjero, el nonacionalista o los otros habitantes (o el gobierno) del Estado en el que (aunque no lo quiera) está integrado. El nacionalismo fundamenta asimismo parte de su indudable éxito con las masas en su habilidad para ocultar (artificialmente) conflictos no resueltos. En Cataluña o el País Vasco, como en el resto de España, existen pobres y ricos, violencia de género, divorcios traumáticos, inseguridad en las calles, robos en viviendas, asesinos múltiples, psicópatas sociales, multitud de imbéciles patológicos que hacen la vida imposible a sus vecinos, depresivos, suicidas, violencia y acoso en las escuelas... El mismo Josep Pla (2017, p. 57) definía al catalán como "un fugitivo. A veces huye de símismo y otras, cuando sigue dentro de sí, se refugia en otras culturas, se extranjeriza, se destruye; escapa intelectual y moralmente. A veces parece

un cobarde y otras un ensimismado orgulloso. A veces parece sufrir de manía persecutoria y otras de engreimiento. Alterna constantemente la avidez con sentimientos de frustración enfermiza". Vivimos la "edad de la ansiedad" y algunos dirigentes políticos (los separatistas) se dedican precisamente a aumentar nuestra ansiedad y estrés..., innecesariamente y de forma colectiva, rompiendo familias, creando conflictos artificiales (lingüísticos y de todo tipo) donde no los había. 
Un último elemento del pensamiento mágico es que el diálogo lo puede todo. Se trata de cifrar la solución del "conflicto" en el diálogo como mero procedimiento, sin necesidad de establecer agenda, contenidos y límites. ${ }^{14}$ Esta tesis bien pensante ignora que el diálogo es imposible con el separatismo pues éste, de llegar a un acuerdo "final" con el Estado, desaparecería. Para el separatismo solo pueden caber acuerdos provisionales (como lo era el Estatuto de autonomía de 2006), que no resuelven ningún conflicto sino que los crea, los mantiene o los agrava. Como movimiento político nace y se mantiene sobre la tesis del agravio y chantaje permanente. Esta es su esencia $y$, por tanto, su mayor amenaza es que un día dejara de poder echarse toda la culpa "a Madrid" y se debatiera de la mejor gestión y las mejores políticas para Cataluña. En ese momento, el votante catalán incluso se podría platear exigir responsabilidades a la Generalitat por el (mal) funcionamiento de los servicios públicos y cambiar su voto a opciones no nacionalistas.

Entonces, ¿̇qué hacer? Recordemos al gran pensador español Salvador de Madariaga (1979, p. 586), ministro durante la II República, europeísta convencido y primer presidente de la Internacional liberal, quien afirmaba ya en pleno siglo XX: "la segunda guerra mundial tiene que abocar a una era de grandes familias de naciones. No es este el momento para dividir una nación ya hecha, sino para integrarla en una nación mayor. No es el momento para multiplicar las republiquitas sino para federar los continentes". La II Guerra Mundial terminó hace más de setenta años, sin embargo, seguimos ignorando lo que Madariaga argumentó, que representa simplemente racionalidad pura y sentido común: ni demasiado grande ni demasiado pequeño; ni demasiado homogéneo, ni demasiado diverso. Hoy como ayer hay que optar entre el "divide y vencerás" y "la unión hace la fuerza", aunque sea reconociendo la diversidad. O recordar los dos principios básicos para la ética y la sabiduría: "concordia oppositorum" y "in medium virtus est".

Hay muchos motivos para luchar contra el separatismo y lo que éste representa. Uno es honrar una narración verídica del pasado, pero otro no menor es la búsqueda de un futuro en concordia y en paz. No solo para España. La necesidad de no multiplicar/dividir todavía más los países del mundo afecta al interés general global de todos: salvaguardar la estabilidad y el equilibrio en el mapa actual de naciones.

\section{REFERENCIAS}

-Arnoldsson, Sverker (2018) Los orígenes de la leyenda Negra española, ed. El Paseo, Sevilla

${ }^{14}$ Cfr Gil Ibáñez, A. "Los límites olvidados del diálogo: magia y realismo", publicado el 1
de octubre de 2017 en http://www elasterisco.es/los-limites-del-dialogo/

EMUI EuroMed University | ISSN 1578-6730 - Nomads. Mediterranean Perspectives | ISSN 1889-7231 (C) 1999, Román Reyes, Fundador y Director · (C) 2016, Progetto Pier Paolo Pasolini 
-Azaña, Manuel (1980) La velada en Benicarló. Diálogo de la guerra de España, ed. Castalia, Madrid

-Borrell, Josep y Llorach, Joan (2015) Las cuentas y los cuentos de la independencia, ed. Los Libros de la Catarata, Madrid

-Elliot, John H. (2018) Catalanes y Escoceses. Unión y Discordia, ed. Taurus, Barcelona

- G. Ibáñez, Alberto

-(coord.) con Marcos Allo, Ramón (2014) A favor de España. El coste de la ruptura, ed. La Esfera de los libros, Madrid

-(2018) La leyenda negra: Historia del odio a España ed. Almuzara, Madrid -Gómez Moreno, Ángel (2017) La huella del león y el Indovinello veronese en La Mancha (Historia, cultura oral, etnografía y genética de poblaciones), ed. Universidad de Granada

-González-Varas, Santiago (2002) España no es diferente, ed. Tecnos, Madrid

-Madariaga, Salvador de (1979) España. Ensayo de historia contemporánea, ed. Espasa-Calpe, Madrid

-Marías, Julián (2010) España inteligible. Razón histórica de las Españas, ed. Alianza, Madrid

-Morales Moya, Antonio (ed.) (2014) 1714: Cataluña en la España del siglo XVIII, ed. Cátedra, Madrid

-Moure Romanillo, Alfonso y Santos Yanguas, Juan (2004) Historia de España: Prehistoria, del primer hombre a las colonizaciones mediterráneas (hasta el siglo III a.C), ed. Espasa-Calpe, Madrid, 2004

-Muñoz Machado, Santiago (2014) Cataluña y las demás Españas, ed. Crítica, Barcelona

-Pla, Josep (2017) Hacerse todas las ilusiones posibles y otras notas dispersas, ed. Destino, Barcelona

-Thomas, Hugh (2003), El imperio español. De Colón a Magallanes, ed. Planeta, Barcelona, 2003.

-Ucelay-Da Cal, Enric (2003) El imperialismo catalán. Prat de la Riba, Cambó, D'Ors y la conquista moral de España, ed. Edhasa, Barcelona

-Varios Autores (2004) Historia de España. Prehistoria: del primer hombre a las colonizaciones mediterráneas (hasta el siglo III), ed. Espasa-Calpe, Madrid

-Zugazagoitia, Julián (1968) Guerra y vicisitudes de los españoles, ed. Librería española, París 